\title{
Leakage of $\mathrm{CO}_{2}$ from Geologic Storage: Role of Secondary Accumulation at Shallow Depth
}

\author{
Karsten Pruess \\ Earth Sciences Division, Lawrence Berkeley National Laboratory \\ University of California, Berkeley, CA 94720 \\ K_Pruess@lbl.gov
}

\begin{abstract}
Geologic storage of $\mathrm{CO}_{2}$ can be a viable technology for reducing atmospheric emissions of greenhouse gases only if it can be demonstrated that leakage from proposed storage reservoirs and associated hazards are small or can be mitigated. Risk assessment must evaluate potential leakage scenarios and develop a rational, mechanistic understanding of $\mathrm{CO}_{2}$ behavior during leakage. Flow of $\mathrm{CO}_{2}$ may be subject to positive feedbacks that could amplify leakage risks and hazards, placing a premium on identifying and avoiding adverse conditions and mechanisms. A scenario that is unfavorable in terms of leakage behavior is formation of a secondary $\mathrm{CO}_{2}$ accumulation at shallow depth. This paper develops a detailed numerical simulation model to investigate $\mathrm{CO}_{2}$ discharge from a secondary accumulation, and evaluates the role of different thermodynamic and hydrogeologic conditions. Our simulations demonstrate self-enhancing as well as self-limiting feedbacks. Condensation of gaseous $\mathrm{CO}_{2}, 3$-phase flow of aqueous phase liquid $\mathrm{CO}_{2}$ - gaseous $\mathrm{CO}_{2}$, and cooling from Joule-Thomson expansion and boiling of liquid $\mathrm{CO}_{2}$ are found to play important roles in the behavior of a $\mathrm{CO}_{2}$ leakage system. We find no evidence that a subsurface accumulation of $\mathrm{CO}_{2}$ at ambient temperatures could give rise to a high-energy discharge, a so-called "pneumatic eruption."
\end{abstract}

Keywords. $\mathrm{CO}_{2}$ leakage; $\mathrm{CO}_{2}$ accumulation; pneumatic eruption; $\mathrm{CO}_{2}$ storage security; threephase flow; numerical simulation. 


\section{Introduction}

Geologic storage of $\mathrm{CO}_{2}$ from large stationary sources (fossil-fueled power plants) would generate large plumes, with linear dimensions of order $10 \mathrm{~km}$ or more (Pruess et al., 2002). $\mathrm{CO}_{2}$ storage sites would be chosen after careful characterization studies, that would especially focus on the ability and integrity of caprock formations to contain the $\mathrm{CO}_{2}$. However, on the anticipated large scale of $\mathrm{CO}_{2}$ plumes it seems likely that caprock imperfections may be encountered, such as fracture zones or faults, that may allow some $\mathrm{CO}_{2}$ to escape from the primary storage formation. Additional leakage risks may arise from pre-existing and improperly abandoned wells. In order to assess the ramifications of $\mathrm{CO}_{2}$ leakage and potential hazards associated with it, it is necessary to develop a sound understanding of the manner in which $\mathrm{CO}_{2}$ would migrate in natural hydrogeological settings. The chief approaches through which the required knowledge base can be developed is (1) studies of natural $\mathrm{CO}_{2}$ reservoirs and discharges, as e.g. in volcanic areas (Chiodini et al., 2004; Evans et al., 2004; Shipton et al., 2004; Todaka et al., 2006), and (2) numerical modeling of actual or hypothesized leakage scenarios, based on a sound understanding of the governing physical and chemical processes, and the thermophysical properties of $\mathrm{CO}_{2}$-brine mixtures (Todesco et al., 2004; Pruess 2004, 2005a, b, 2007).

Empirical evidence from tectonically active regions with natural $\mathrm{CO}_{2}$ manifestations suggests that $\mathrm{CO}_{2}$ leakage would most likely occur as "diffuse degassing." However, in the volcanology literature the possibility of a "pneumatic eruption" has been suggested, that would be powered by the mechanical energy of compression accumulated in a volume of high-pressure fluid (Giggenbach, 1991; Fischer et al., 1996; Browne and Lawless, 2001). While the notion of a pneumatic eruption associated with $\mathrm{CO}_{2}$ sequestration remains hypothetical, the possibility that a $\mathrm{CO}_{2}$ discharge could be accompanied by substantial energy release has not been ruled out. Indeed, the thermophysical and chemical properties of $\mathrm{CO}_{2}$ suggest a potential for self-enhancing feedback after a discharge gets underway. Relevant properties include (1) lower density than aqueous phase, providing a potential for buoyant flow and pressure increases at shallow depth, (2) much lower viscosity than water, providing for much greater volumetric flow rates for given driving pressures, and (3) much larger compressibility than aqueous fluids, providing for much greater volume expansion upon depressurization. $\mathrm{CO}_{2}$ may also dissolve some rock minerals, 
thereby enhancing porosity and permeability of flow paths (Gherardi et al., 2007). Last but not least, pressurization effects associated with $\mathrm{CO}_{2}$ storage may induce movement along preexisting fractures and faults, with a potential for inducing seismicity and enhancing permeability and flow (Streit and Hillis, 2004; Rutqvist and Tsang, 2005; Rutqvist et al., 2007).

Several lines of evidence suggest that $\mathrm{CO}_{2}$ discharges are subject not only to selfenhancement, but to self-limiting mechanisms as well. Examples include observations of natural " $\mathrm{CO}_{2}$ geysers," whose eruptions are powered not by thermal energy but by mechanical energy of compression (Shipton et al., 2004); blow-outs from oil wells in reservoirs where $\mathrm{CO}_{2}$ is injected to enhance oil recovery (Skinner, 2003); and numerical simulation studies of $\mathrm{CO}_{2}$ discharge from a fault (Pruess, 2005). These examples demonstrate positive feedback processes that amplify an initially weak flow of $\mathrm{CO}_{2}$, but they clearly show negative feedbacks as well, that limit the magnitude and time scale of discharges, and prevent a runaway process.

The questions driving this research are: what positive feedback processes could exacerbate $\mathrm{CO}_{2}$ leakage after it gets started? How strong and persistent can such feedbacks be? Are negative feedbacks inevitable, and will they always act to prevent a $\mathrm{CO}_{2}$ discharge from turning into a high-energy runaway process? We address these questions by investigating specific leakage scenarios, and using detailed numerical simulation to evaluate their flow dynamics and discharge behavior. It must be acknowledged at the outset that, strictly speaking, no collection of scenario analyses will ever suffice to conclusively prove that a runaway, eruptive discharge is not possible. Indeed, how can we be sure that we have imagined, let alone accurately analyzed, every possible combination of factors that could enable strong positive feedbacks? Experience with natural $\mathrm{CO}_{2}$ discharge suggests that, if $\mathrm{CO}_{2}$ does leak from an anthropogenic storage reservoir, this would most likely occur in a diffuse manner at low rates (Chiodini et al., 2004), and would raise little concern about storage security. There is an unending variety of $\mathrm{CO}_{2}$ leakage scenarios that may be imagined, but a safety demonstration of $\mathrm{CO}_{2}$ geologic storage must place a premium on identifying and investigating scenarios with a potential for self-enhancement and runaway, rare as they may be, because such scenarios could dominate overall storage risk and public acceptance of $\mathrm{CO}_{2}$ storage (Birkholzer et al., 2006; Pruess, 2007). 
It may appear that the scenario of greatest concern would be one in which highpermeability discharge paths would directly connect the deep $\mathrm{CO}_{2}$ storage reservoir with the land surface. Such pathways may be provided by extensive sub-vertical fault and fracture zones, or by improperly abandoned wells, that may not have been recognized during site characterization. However, there is evidence for strong self-limiting effects during upflow of $\mathrm{CO}_{2}$. When $\mathrm{CO}_{2}$ rises from depth it is subject to depressurization and large volume expansion, which is accompanied by strong Joule-Thomson cooling (Katz, 1990; Pruess, 2005b; Oldenburg, 2007). Fig. 1 shows temperatures that would be reached upon adiabatic (= no external heat supply) expansion of $\mathrm{CO}_{2}$ to atmospheric pressure $(1.013$ bar), starting from ambient pressure and temperature conditions at different depths. The ambient conditions correspond to a hydrostatic pressure gradient of approximately $0.1 \mathrm{bar} / \mathrm{m}$ in a typical crustal geothermal gradient of 0.03 ${ }^{\circ} \mathrm{C} / \mathrm{m}$, for a land surface temperature of $15{ }^{\circ} \mathrm{C}$. The data in Fig. 1 were calculated from the water and $\mathrm{CO}_{2}$ property correlations given by (IFC, 1967) and (Altunin, 1975), respectively. It is seen that adiabatic cooling can generate very low temperatures that approach the triple point of $\mathrm{CO}_{2}$, $\mathrm{T}_{3}=-56.4{ }^{\circ} \mathrm{C}$, for expansion from $580 \mathrm{~m}$ depth. Even lower temperatures would be reached for adiabatic expansion from greater depth, where $\mathrm{CO}_{2}$ is at supercritical pressures and has considerably lower specific enthalpy. Expansion of supercritical $\mathrm{CO}_{2}$ without external heat supply will cause temperatures to drop below the triple point of $\mathrm{CO}_{2}$ and will generate first liquid and then solid $\mathrm{CO}_{2}$ (dry ice). $\mathrm{CO}_{2}$ blowouts from deep wells during enhanced oil recovery operations have indeed shown extreme cooling effects, with discharge of dry ice from the wells (Skinner, 2003).

The strong cooling during expansion of $\mathrm{CO}_{2}$ limits $\mathrm{CO}_{2}$ fluxes. Our earlier work has shown that cooling gives rise to condensation of gaseous $\mathrm{CO}_{2}$, promoting the evolution of 3phase conditions (aqueous phase - liquid $\mathrm{CO}_{2}-$ gaseous $\mathrm{CO}_{2}$ ) with strong flow interference and low effective permeabilities (Pruess, 2005a, b). This suggests that a direct discharge of $\mathrm{CO}_{2}$ all the way from a deep storage reservoir to the land surface could not sustain high flow rates. A more feasible scenario for generating a "strong" $\mathrm{CO}_{2}$ discharge at the land surface may involve an indirect process whereby $\mathrm{CO}_{2}$ first accumulates in a secondary "parasitic" storage reservoir at shallower depths (Fig. 2). If such an accumulation occurs at "moderate" flow rates, then heat 
transfer from the surrounding formations to the flowing $\mathrm{CO}_{2}$ would be sufficient to avoid strong cooling effects. $\mathrm{CO}_{2}$ stored at shallow levels is at lower pressures, has considerably greater specific enthalpy than deep, high-pressure $\mathrm{CO}_{2}$, and accordingly will experience much weaker

cooling effects during discharge to the land surface. In this paper we use numerical simulation to investigate the kind of leakage scenario depicted in Fig. 2, and to study the dependence of leakage behavior on the main problem parameters, such as leakage rate, fault permeability, and others. As will be seen, a key element in the dynamics of a leakage system as depicted in Fig. 2 is the tradeoff between the magnitude of the secondary $\mathrm{CO}_{2}$ accumulation, and the ease with which the accumulated $\mathrm{CO}_{2}$ may be discharged to the land surface.

The organization of the paper is as follows. We first describe our choice of reference scenario and modeling approach. This is followed by a presentation of simulation results, and a discussion of flow behavior and process dynamics of leaking $\mathrm{CO}_{2}$. Subsequently we vary system parameters to explore a range of possible evolutions and outcomes. The paper concludes with a discussion of our findings and suggestions for future work.

\section{Reference Scenario and Modeling Approach}

One can conceive of an unlimited variety of faulted aquifer systems that could provide pathways for upward $\mathrm{CO}_{2}$ migration and enable a shallow secondary accumulation of $\mathrm{CO}_{2}$ to form. In this paper we investigate leakage scenarios of the kind depicted in Fig. 2, because they may provide a possibility of self-enhancing feedbacks that would accelerate leakage. Once a spill point is reached and $\mathrm{CO}_{2}$ discharge gets underway, the larger mobility (lower viscosity) of $\mathrm{CO}_{2}$ as compared to aqueous fluids provides a potential for self-enhancing flows, as water in the outflow path is being replaced with less-viscous $\mathrm{CO}_{2}$. Upflow would be further increased by the lower density (smaller gravity body force) of $\mathrm{CO}_{2}$ relative to water. The combined effects of lower viscosity and density of $\mathrm{CO}_{2}$ on leakage could accelerate depressurization of the shallow $\mathrm{CO}_{2}$ accumulation which would be accompanied by large volumetric expansion and further density decrease. These effects could further amplify self-enhancing mechanisms.

The discharge scenario just outlined would engage self-limiting effects as well. Even though $\mathrm{CO}_{2}$ has lower viscosity than water, volumetric flow rates in the outflow path towards the 
land surface do not necessarily increase when water is being replaced by $\mathrm{CO}_{2}$. Volumetric flow rates are determined by an interplay between driving forces and effective fluid mobility. The latter is subject to relative permeability effects, and may actually decrease even when a lowerviscosity fluid becomes involved in the flow. Indeed, the effective total mobility of a multiphase mixture is

$$
\mathrm{m}=\sum_{\beta} \frac{\mathrm{k}_{\mathrm{r} \beta}}{\mu_{\beta}}
$$

where the summation is over all phases $\beta$. Relative permeabilities are small for small phase saturations, so that total fluid mobility in two-phase conditions (aqueous - gaseous $\mathrm{CO}_{2}$ ) can be smaller, even much smaller, than mobility for single-phase aqueous conditions, in spite of the fact that the viscosity of the $\mathrm{CO}_{2}$-rich phase will be much smaller than that of the aqueous phase. As gas saturations increase during flow, initially due to $\mathrm{CO}_{2}$ immiscibly displacing resident water, and later, on a much slower time scale, due to water dissolving into the flowing $\mathrm{CO}_{2}$ stream, gas $\left(\mathrm{CO}_{2}\right.$-rich) phase relative permeabilities will increase. Under conditions where the flow system reaches a final state with single-phase gas flow (all water removed), eventual fluid mobility $\mathrm{m}_{\mathrm{g}}=\mathrm{k}_{\mathrm{rg}} / \mu_{\mathrm{g}} \Rightarrow 1 / \mu_{\mathrm{g}}$ will exceed mobility $\mathrm{m}_{\mathrm{aq}}=1 / \mu_{\mathrm{aq}}$ of the aqueous phase by a factor $\mathrm{m}_{\mathrm{g}} / \mathrm{m}_{\mathrm{aq}}=\mu_{\mathrm{aq}} / \mu_{\mathrm{g}}$ which, depending on thermodynamic conditions and aqueous phase salinity, may be of order 10-30.

Absolute and relative permeabilities of the outflow path play multiple and conflicting roles in enabling $\mathrm{CO}_{2}$ to first accumulate and subsequently to discharge. Large flow resistance in the outflow channel will enhance pressurization of the accumulating $\mathrm{CO}_{2}$ bubble, and will therefore increase the density and inventory of $\mathrm{CO}_{2}$ that is available for sustaining a discharge. Such effects can be very large at near-critical pressures. At the same time, such flow resistance will limit the growth of outflow rates after discharge gets underway. An important objective of our studies is to gain insight into how these opposing effects may play out.

For definiteness we begin the investigation by considering a system as depicted in Fig. 3. We consider a 2-D vertical section through a $20 \mathrm{~m}$ thick aquifer that is bounded by a blind fault 
on the left and is intersected by another fault that extends all the way to the land surface on the right. The faults are assumed $2 \mathrm{~m}$ wide and sub-vertical dipping at an angle of $70^{\circ}$; the aquifer is dipping at $20^{\circ}$. The purpose of this geometric arrangement is to enable buoyant $\mathrm{CO}_{2}$ to accumulate in the aquifer, and to create a sizeable inventory before $\mathrm{CO}_{2}$ would reach the spill point at the fault intersection on the right. The $\mathrm{CO}_{2}$ pathway from the deep geologic storage reservoir to the shallow portion of the flow system shown in Fig. 3 is not modeled. Instead, we assume that a pathway exists that allows deep $\mathrm{CO}_{2}$ to reach the blind fault on the left of Fig. 3 . Upward migration of $\mathrm{CO}_{2}$ along the fault is represented by means of a source term at the bottom of the blind fault. For the reference case we select uniform properties of permeability $\mathrm{k}=10^{-13} \mathrm{~m}^{2}$ (100 millidarcy) and porosity $\phi=0.12$. As will be seen below, during $\mathrm{CO}_{2}$ migration three-phase conditions evolve, necessitating specifications of three-phase relative permeabilites. We use the formulation given by Stone (1970) with an exponent of 3.0 and irreducible saturations of $\mathrm{S}_{\mathrm{ar}}=$ $0.30, \mathrm{~S}_{\mathrm{lr}}=0.01$ and $\mathrm{S}_{\mathrm{gr}}=0.01$ for aqueous, liquid, and gaseous $\mathrm{CO}_{2}$ phases, respectively. Capillary pressures are neglected. Thermal parameters include rock specific heat of $c_{R}=920$ $\mathrm{J} / \mathrm{kg} /{ }^{\circ} \mathrm{C}$, rock grain density $\rho_{\mathrm{R}}=2600 \mathrm{~kg} / \mathrm{m}^{3}$, and formation thermal conductivity of $2.51 \mathrm{~W} / \mathrm{m} /{ }^{\circ} \mathrm{C}$. For the $1 \mathrm{~m}$ thick section modeled here, we assume a $\mathrm{CO}_{2}$ injection rate of $16 \times 10^{-4} \mathrm{~kg} / \mathrm{s}$. If leakage were to occur over a $100 \mathrm{~m}$ fault length, this would correspond to a total $\mathrm{CO}_{2}$ rate of 0.16 $\mathrm{kg} / \mathrm{s}$, which is approximately $0.5 \%$ of the $\mathrm{CO}_{2}$ injection rate at the Sleipner Vest $\mathrm{CO}_{2}$ storage project (Arts et al., 2004).

Flow of $\mathrm{CO}_{2}$-brine mixtures is modeled with our general-purpose simulation code TOUGH2, using a special fluid property module "EOSM" that can represent all possible phase combinations in systems of sub-critical $\mathrm{CO}_{2}$ and brine, as well as transitions between sub- and supercritical conditions (Pruess, 2004). Thermophysical properties of $\mathrm{CO}_{2}$ are represented, generally within experimental accuracy, by the correlations of Altunin (1975), as incorporated into a computer program that was kindly provided to us by Victor Malkovsky of IGEM, Moscow, Russia. As initial conditions for most simulations we assume hydrostatic equilibrium of pure water (no salinity) in an ambient geothermal gradient. Geothermal gradients in sedimentary basins commonly range from $0.015{ }^{\circ} \mathrm{C} / \mathrm{m}$ to $0.04{ }^{\circ} \mathrm{C} / \mathrm{m}$ or more $\left(15-40^{\circ} \mathrm{C} / \mathrm{km}\right.$; Erdlac et al., 2007). For our reference case we choose a value of $|\nabla T|=0.0357^{\circ} \mathrm{C} / \mathrm{m}$; the corresponding equilibrium temperature and pressure conditions as functions of depth are obtained by running a 
water-only system to steady state against land surface conditions of $\mathrm{T}=15^{\circ} \mathrm{C}, \mathrm{P}=1.013$ bar, while maintaining ambient temperature at the bottom of the system. For the geometric parameters chosen, the $\mathrm{CO}_{2}$ injection point is at a true depth of $181.93 \mathrm{~m}$. For a land surface temperature of $15{ }^{\circ} \mathrm{C}$, ambient conditions at the bottom are then found to be $(\mathrm{T}, \mathrm{P})=\left(21.4{ }^{\circ} \mathrm{C}\right.$, 18.9 bar). $\mathrm{CO}_{2}$ saturation pressure at $21.4{ }^{\circ} \mathrm{C}$ is 59.24 bar, so that $\mathrm{CO}_{2}$ would be gaseous at the initial conditions at the injection point. However, pressures increase in response to $\mathrm{CO}_{2}$ injection and may reach and exceed the saturation pressure. When this happens, gaseous $\mathrm{CO}_{2}$ will condense to form liquid $\mathrm{CO}_{2}$, and in general we may have three fluid phases present, aqueous phase - gaseous $\mathrm{CO}_{2}$ - liquid $\mathrm{CO}_{2}$. Our TOUGH2/EOSM code can treat these kinds of phase transitions, including accompanying multiphase flow and latent heat effects. As will be seen, thermal effects arising from $\mathrm{CO}_{2}$ decompression, as well as condensation and boiling, are an important aspect of system behavior. In particular, heat transfer between flowing $\mathrm{CO}_{2}$ and the surrounding geologic formations can be important, and is here modeled by conceptualizing the wall rocks bounding the faults as semi-infinite half-spaces, and using the semi-analytical technique of Vinsome and Westerveld (1980). More details about the heat transfer treatment are given in (Pruess, 2005b).

For numerical simulation, the flow domain must be discretized in space. Vertical discretization in the aquifer is $2 \mathrm{~m}$. Horizontal discretization is $2 \mathrm{~m}$ for the first $10 \mathrm{~m}$ next to the faults, and is $5 \mathrm{~m}$ in the interior. The faults are modeled as 1-D columns with a discretization of 2 $\mathrm{m}$ for the bottom and top $10 \mathrm{~m}$, and $5 \mathrm{~m}$ in between. Test calculations not reported here have confirmed that these discretizations are adequate for resolving gradients in temperature, pressure, and saturation.

\section{Results - Reference Case}

Results for the reference case are given in Figs. 4-6. Fig. 4 shows ouflow rates of water and $\mathrm{CO}_{2}$ at the land surface, along with fluid pressure at the $\mathrm{CO}_{2}$ injection point. In response to $\mathrm{CO}_{2}$ injection pressures increase quickly, and after about $2.5 \times 10^{5} \mathrm{~s}$ approach the $\mathrm{CO}_{2}$ saturation pressure of 59.2 bar at injection temperature of $21.4{ }^{\circ} \mathrm{C}$, indicating attainment of three-phase conditions. The pressurization induces water discharge to the land surface at rates that increase rapidly with time during the early period, when injection pressures also increase rapidly. After 
three-phase conditions are reached, there is a one-to-one correspondence between $\mathrm{CO}_{2}$ pressures and temperatures. This dramatically slows down further pressure increases and thereby strongly reduces additional increases in water discharge rates as well. There is a large and very brief water pulse at $\mathrm{t}=1.4 \times 10^{7} \mathrm{~s}$, followed by a slower decline and an eventual cessation of water outflow at $\mathrm{t}=6.1 \times 10^{8} \mathrm{~s}$. The large water pulse coincides with the beginning of discharge of free gaseous $\mathrm{CO}_{2}$. As free-phase $\mathrm{CO}_{2}$ approaches the land surface, there is a strong volumetric expansion from declining pressures, and it is this expansion that causes the large water pulse at $\mathrm{t}$ $=1.4 \times 10^{7} \mathrm{~s} . \mathrm{CO}_{2}$ outflow rates increase with time, and at $\mathrm{t}=5.91 \times 10^{7} \mathrm{~s}$ reach a maximum value of $38.7 \times 10^{-4} \mathrm{~kg} / \mathrm{s}$. This exceeds the applied injection rate of $16 \times 10^{-4} \mathrm{~kg} / \mathrm{s}$ by a factor 2.42 , demonstrating positive feedback effects from $\mathrm{CO}_{2}$ replacing water in the outflow channel. However, the discharge enhancement is short-lived and gives way to a gradual decline. At $\mathrm{t}=10^{8}$ $\mathrm{s}, \mathrm{CO}_{2}$ outflow exceeds injection rate by less than $3 \%$, and subsequently steady flow conditions are approached.

The flow dynamics can be understood in terms of two- and three-phase relative permeability effects due to the changing phase compositions of water- $\mathrm{CO}_{2}$ mixtures. Different points of the flow system go through similar changes in thermodynamic conditions after they are reached by free-phase $\mathrm{CO}_{2}$, with changes in the deeper parts occurring at earlier times. We will discuss the interrelated changes between phase saturations and fluid temperatures and pressures for monitoring point (2), located at the entry from the lower fault to the aquifer. When a free $\mathrm{CO}_{2}$-phase first evolves at point (2), after $\mathrm{t}=1.4 \times 10^{6} \mathrm{~s}$, this is accompanied by a small increase in temperature from heat-of-dissolution effects (Fig. 5). The approach to three-phase conditions at $\mathrm{t}=9.6 \times 10^{6} \mathrm{~s}$ is marked by a precipitous temperature decline, which arises from the consumption of latent heat as liquid $\mathrm{CO}_{2}$ at the top of the three-phase zone boils into gas. After three-phase conditions are reached, temperatures increase in response to pressure increase, but after about $2 \times 10^{7} \mathrm{~s}$ liquid saturation and temperature decline, in response to increasing $\mathrm{CO}_{2}$ discharge at the top that is accompanied by boil-off of liquid $\mathrm{CO}_{2}$. Fig. 6 shows the extent of three-phase conditions in the aquifer at $\mathrm{t}=4.3 \times 10^{7} \mathrm{~s}$. The $\mathrm{CO}_{2}$ discharge maximum at $\mathrm{t}=$ $5.91 \times 10^{7} \mathrm{~s}$ coincides with a rapid boil-off of remaining liquid $\mathrm{CO}_{2}$ and a large increase in saturation of gaseous $\mathrm{CO}_{2}$, due to strong expansion effects as pressures decline throughout the system. 
From the standpoint of multiphase flow, the main significance of three-phase conditions is that relative permeabilities to all phases tend to be low due to strong phase interference. As a consequence, there is a marked reduction in total fluid mobility in three-phase regions (Eq. 1). Due to the much higher density of liquid as compared to gaseous $\mathrm{CO}_{2}$, the inventory of stored $\mathrm{CO}_{2}$ will greatly increase when liquid conditions evolve. This provides a potential for generating a stronger $\mathrm{CO}_{2}$ discharge at the land surface, but will be opposed by the reduction in fluid mobility, which will reduce attainable discharge rates.

Fig. 4 shows that fluid pressures at the injection point (monitoring point 1 in Fig. 3) reach as high as 63 bar, before eventually declining strongly as the system moves towards increasing gas saturations and increased fluid mobility throughout. To determine whether such large pressures can be realistically expected at rather shallow depths (our injection point is at $182 \mathrm{~m}$ depth), we have analyzed fluid pressures in static columns of $\mathrm{CO}_{2}$ that would extend upward from a deep storage reservoir. Fig. 7 shows that for primary storage reservoirs at depths from 1,000 - 2,000 m, pressures far in excess of 60 bar can be generated at shallow depths, indicating that the fluid pressures implied by the discharge scenario presented above are not unrealistically large.

\section{Sensitivity Studies}

\subsection{Injection Rate}

Fig. 8 compares $\mathrm{CO}_{2}$ discharge rates at the land surface for three cases whose injection rates differ by a factor of 1.25 . Although these rate differences are modest, they lead to dramatic changes in discharge response at the land surface. For the lower rate case the maximum $\mathrm{CO}_{2}$ discharge rate is reached earlier than for the reference case, and the maximum enhancement relative to the injection rate is a modest factor 1.74 , as compared to 2.42 for the reference case. For the largest injection rate, maximum $\mathrm{CO}_{2}$ discharge occurs later, and discharge is enhanced relative to injection rate by a larger factor 3.17. Prior to reaching the maximum discharge, the higher rate case goes through two periods where rates almost stabilize, before resuming a further increase. 
The strong sensitivity to injection rate can be explained in terms of differences in the evolution of phase conditions. In the reference case $\left(\mathrm{q}_{\mathrm{inj}}=16 \times 10^{-4} \mathrm{~kg} / \mathrm{s}\right)$, the maximum extent of 3-phase conditions reaches well into the aquifer (see Fig. 6), but no liquid $\mathrm{CO}_{2}$ ever reaches the upper fault. In contrast, in the low-rate case, three-phase conditions remain confined to the lower part of the lower fault, never reaching the aquifer, while in the high-rate case, they extend all the way into the upper fault. The two periods during which rate increases almost level off in the high-rate case are associated with three-phase conditions evolving at the top of the lower fault (around $23 \times 10^{6} \mathrm{~s}$ ) and three-phase conditions reaching the bottom of the upper fault (around $35 \times 10^{6} \mathrm{~s}$ ). In both time periods it is the low effective fluid mobility in three-phase zones that reduces the rate of flow rate increase, again dramatizing the crucial role of phase conditions in the evolution of the system. Fig. 9 shows saturations of liquid and gaseous $\mathrm{CO}_{2}$ in the upper fault for the higher-rate case at $\mathrm{t}=47.3 \times 10^{6} \mathrm{~s}$. It is seen that temperatures reach a sharp minimum of about $7.5^{\circ} \mathrm{C}$ at the top of the three-phase zone, due to localized boiling of liquid $\mathrm{CO}_{2}$ into gas. Boiling rates and associated temperature drops increase dramatically with applied injection rate. This prevents us from simulating cases with rates higher than $20 \times 10^{-4} \mathrm{~kg} / \mathrm{s}$, because then temperatures drop to the range where formation of hydrate phases and water ice would occur, which currently can not be treated with our simulator.

\subsection{Permeability of Upper Fault}

Varying the permeability of the upper fault shows the crucial role of flow resistance in the outflow pathway. For a fixed injection rate, lower permeability will generate larger pressures, giving rise to formation of more extensive regions with liquid $\mathrm{CO}_{2}$ and hence three-phase conditions with their reduced fluid mobility. While these factors would be conducive to storing larger amounts of $\mathrm{CO}_{2}$ with a greater inventory of compressive energy, lower permeability will also reduce flow rates in the outflow pathway. Fig. 10 shows that the effects are dramatic: lower fault permeability considerably delays the appearance of maximum discharge and greatly increases its magnitude; the maximum ratio of outflow to inflow at an upper fault permeability of $80 \times 10^{-15} \mathrm{~m}^{2}$ is 3.6. These effects are due the increased extent of three-phase conditions brought on by lower fault permeability. For the case with a large fault permeability of $200 \times 10^{-15} \mathrm{~m}^{2}$, pressurization due to the applied $\mathrm{CO}_{2}$ injection is insufficient to ever form three-phase 
conditions. The result is a featureless discharge curve, with only miniscule enhancement relative to the injection rate.

\subsection{Approximate Invariance with Respect to Flowrate:Permeability}

The equations governing multiphase mass and heat flow in the fault-aquifer system are invariant when injection rate and absolute permeability are scaled by the same factor $\lambda$, and time is scaled by the inverse of that factor, $\left(\mathrm{q}_{\mathrm{inj}}, \mathrm{k}, \mathrm{t}\right)==>\left(\lambda \mathrm{q}_{\mathrm{inj}}, \lambda \mathrm{k}, \mathrm{t} / \lambda\right)$, except for contributions of conductive heat flow within the system, and conductive heat exchange with the surroundings (Pruess, 2004). To test this (approximate) invariance, we performed a series of calculations with $\lambda$ in the range $0.05 \leq \lambda \leq 100$, relative to a reference permeability of $10^{-13} \mathrm{~m}^{2}$. The results, using a geothermal gradient of $0.03{ }^{\circ} \mathrm{C} / \mathrm{m}$, are plotted in Fig. 11 in the form of the discharge-to-injection ratio, $\mathrm{q}_{\mathrm{dis}} / \mathrm{q}_{\mathrm{inj}}$, versus total injected mass. It is seen that the normalized discharge curves indeed almost coincide for the cases with higher rates and permeabilities, $1 \leq \lambda \leq 100$. There is a trend of the discharge maximum occurring slightly later for larger $\mathrm{CO}_{2}$ rates, which can be understood by noting that heat conduction from the surroundings is less able to keep up with Joule-Thomson and evaporative cooling. For small rates and permeabilities, $\lambda \leq 0.05$, discharge increases more rapidly at early times and reaches maximum values that are smaller in magnitude and occur at earlier times. Based on detailed inspection of the simulations, this behavior is explained in terms of reduced heat consumption during $\mathrm{CO}_{2}$ expansion and boiling. This enables more sustained heat supply from the surroundings, which reduces the extent of 3-phase conditions and increases fluid mobility.

\subsection{Relative Permeability}

3-phase relative permeabilities are difficult to measure, and no data have been reported for the system water - liquid $\mathrm{CO}_{2}-$ gaseous $\mathrm{CO}_{2}$. The simulations reported above all use a formulation due to Stone (1970) that has been commonly employed in petroleum reservoir simulation, as well as in the study of non-aqueous phase liquid (NAPL) contamination problems in the vadose zone. Fig. 12 compares land surface discharges of water and $\mathrm{CO}_{2}$ for the reference case with simulation results obtained for linear relative permeabilities (relative permeability for each phase equal to saturation). In the latter case, fluid mobilities remain much larger (Eq. 1), and accordingly, there is considerably less pressurization and associated discharge enhancement. 
With linear relative permeabilites, we obtain only a weak water "burp," and $\mathrm{CO}_{2}$ discharge commences much sooner and with less enhancement as well. When different fluid phases intermix in a porous medium we expect strong phase interference effects with small relative permeabilities at intermediate saturations. However, linear relative permeabilities may be applicable for larger-scale systems, in which phase segregation would give rise to "side-by-side" flow.

\subsection{Geothermal Gradient}

The final sensitivity evaluation presented here involves geothermal gradients. Fig. 13 shows simulations for three different values of the geothermal gradient, and also includes a simulation where the temperature of the entire flow system is initialized at the land surface temperature of $15{ }^{\circ} \mathrm{C}(\operatorname{grad}(\mathrm{T})=0)$. For larger temperature gradients, $\mathrm{CO}_{2}$ outflow rates are seen to increase more rapidly, and to peak at earlier time and smaller values. This is explained by the greater supply of thermal energy at larger gradients, which reduces the role of 3-phase conditions and associated reductions in fluid mobility.

\section{Concluding Remarks}

This paper has investigated the migration of $\mathrm{CO}_{2}$ up a fault zone, followed by accumulation in a secondary, shallow storage reservoir, and eventual discharge at the land surface along another fault. The flow system was purposefully set up to provide opportunities for positive feedback processes, and our numerical simulations indeed demonstrated water as well as $\mathrm{CO}_{2}$ discharges at the land surface that for limited time periods were considerably enhanced relative to $\mathrm{CO}_{2}$ injection rates at depth. $\mathrm{CO}_{2}$ discharge at the land surface may be preceded by outflow of water, that culminates in a brief period of enhanced rates ("burp") just prior to start of $\mathrm{CO}_{2}$ flow.

The simulations revealed a complex interplay of multiphase flow processes, cooling effects from decompression of gaseous $\mathrm{CO}_{2}$, condensation and boiling of liquid $\mathrm{CO}_{2}$, and heat exchange between flowing $\mathrm{CO}_{2}$ and surrounding formations. This gives rise to positive feedbacks that can cause temporary enhancement of $\mathrm{CO}_{2}$ discharge at the land surface by factors of 2-3 relative to flow rates at depth. Negative (flow-limiting) feedbacks were identified as well, 
including reduction of fluid mobility in regions where both a liquid and a gaseous $\mathrm{CO}_{2}$-rich phase are present, and cooling effects from Joule-Thomson expansion and boiling of liquid $\mathrm{CO}_{2}$ into gas. $\mathrm{CO}_{2}$ discharge rates are limited not only by negative feedbacks, but also by the limited fluid supply from depth. Specific observations from the numerical simulations are as follows.

- "Strong" discharge enhancements (exceeding a factor 2) occur only when three-phase conditions (aqueous phase - liquid $\mathrm{CO}_{2}$ - gaseous $\mathrm{CO}_{2}$ ) evolve at relatively shallow depths. Such conditions reduce overall fluid mobility, thereby increasing fluid pressures and providing for a larger accumulation of $\mathrm{CO}_{2}$. This means that more mass and energy will be available to drive and sustain an enhanced discharge, but flow resistance to discharging $\mathrm{CO}_{2}$ will also be enhanced and will limit flow rates.

- Three-phase conditions are always associated with significant boiling and localized temperature decline in boiling zones.

- The maximum discharge enhancement occurs as liquid $\mathrm{CO}_{2}$ in the three-phase zones is boiling off.

With increasing depth of the primary storage reservoir, flow paths for $\mathrm{CO}_{2}$ towards the land surface would become longer, and there likely would be more barriers to flow. For these reasons it is generally assumed that the security of $\mathrm{CO}_{2}$ storage will increase when $\mathrm{CO}_{2}$ is placed at greater depth. However, the overpressures in excess of hydrostatic potentially generated by $\mathrm{CO}_{2}$ at shallow depths increase with the depth of the primary storage reservoir. The manner in which these opposing effects - longer flow paths and more barriers vs. larger overpressures may trade off is not obvious, and may depend on site-specific conditions.

Our studies have shown an interplay of positive and negative feedbacks. No evidence was found that $\mathrm{CO}_{2}$ could discharge in the form of a high-energy runaway process, even for a scenario that was designed to facilitate such behavior. However, our simulations have neglected geochemically and/or geomechanically coupled processes that conceivably could amplify $\mathrm{CO}_{2}$ discharges. Indeed, $\mathrm{CO}_{2}$ migrating up a fault could dissolve carbonates, and pressurization associated with $\mathrm{CO}_{2}$ migration could cause movement along faults. Both effects could enhance 
formation permeabilities and give rise to increased $\mathrm{CO}_{2}$ flow rates, and further studies are needed to evaluate their potential impacts on $\mathrm{CO}_{2}$ containment and leakage. In addition, the critical role of three-phase relative permeability points to the need for experimental studies to better constrain multiphase interference in $\mathrm{CO}_{2}$ leakage studies. 


\section{Acknowledgement}

Thanks are due to Curt Oldenburg for a careful review of the manuscript and the suggestion of improvements. This work was supported by the Zero Emission Research and Technology project (ZERT) under Contract No. DE-AC02-05CH11231 with the U.S. Department of Energy.

\section{References}

Altunin, V.V. Thermophysical Properties of Carbon Dioxide, Publishing House of Standards, 551 pp., Moscow, 1975 (in Russian).

Arts, R., A. Chadwick and O. Eiken. Recent Time-Lapse Seismic Data Show No Indication of Leakage at the Sleipner CO2-Injection Site, Proceedings, GHGT-7, 7th International Conference on Greenhouse Gas Control Technologies, Vancouver, Canada, pp. 653-662, 2004.

Birkholzer, J., K. Pruess, J. Lewicki, J. Rutqvist, C.F. Tsang and A. Karimjee. Large Releases from CO2 Storage Reservoirs: Analogs, Scenarios, and Modeling Needs, presented at GHGT-8, 8th International Conference on Greenhouse Gas Control Technologies, Trondheim, Norway, June 2006.

Browne, P.R.L. and J.V. Lawless. Characteristics of Hydrothermal Eruptions, with Examples from New Zealand and Elsewhere, Earth-Science Rev., Vol. 52, pp. 299-331, 2001.

Chiodini, G., C. Cardellini, A. Amato, E. Boschi, S. Caliro, F. Frondini and G. Ventura. Carbon Dioxide Degassing and Seismogenesis in Central and Southern Italy, Geophys. Res. Let., Vol. 31, L07615, doi: 10.1029/2004GL019480, 2004.

Erdlac, R.J. Jr., L. Armour, R. Lee, S. Snyder, M. Sorensen, M. Matteucci, and J. Horton. Ongoing Resource Assessment of Geothermal Energy from Sedimentary Basins in Texas, Proceedings, Thirty-Second Workshop on Geothermal Reservoir Engineering, Stanford University, Stanford, CA, January 2007. 
Evans, J.P., J.Heath, Z.K. Shipton, P.T. Kolesar, B. Dockrill, A. Williams, D. Kirchner, T.E. Lachmar and S.T. Nelson. Natural Leaking CO2-charged Systems as Analogs for Geologic Sequestration Sites, paper presented at Third Annual Conference on Carbon Capture and Sequestration, Alexandria, VA, May 2004.

Fischer, T.P., G.B. Arehart, N.C. Sturchio and S.N. Williams. The Relationship between Fumarole Gas Composition and Eruptive Activity at Galeras Volcano, Colombia, Geology, Vol. 24, No. 6, pp. 531-534, 1996.

Gherardi, F., T. Xu and K. Pruess. Numerical Modeling of Self-limiting and Self-enhancing Caprock Alteration Induced by $\mathrm{CO}_{2}$ Storage in a Depleted Gas Reservoir, submitted to Chem. Geol., February 2007.

Giggenbach, W.F., Y. Sano, and H.U. Schmincke. CO2-rich Gases from Lakes Nyos and Monoun, Cameroon; Lacher See, Germany; Dieng, Indonesia, and Mt. Gambier, Australia - Variations on a Common Theme, J. Volcanol. Geotherm. Res., Vol. 45, pp. 311-323, 1991.

IFC (International Formulation Committee). A Formulation of the Thermodynamic Properties of Ordinary Water Substance, IFC Secretariat, Düsseldorf, Germany, 1967.

Katz, D.L. and R.L. Lee. Natural Gas Engineering, McGraw-Hill Publ. Comp., New York, NY, 1990.

Oldenburg, C. Joule-Thomson Cooling due to CO2 Injection into Natural Gas Reservoirs, Energy Conversion and Management, Vol. 48, pp. 1808-1815, June 2007.

Pruess, K. The TOUGH Codes-A Family of Simulation Tools for Multiphase Flow and Transport Processes in Permeable Media, Vadose Zone J., Vol. 3, pp. 738 - 746, 2004.

Pruess, K. Numerical Simulation of $\mathrm{CO}_{2}$ Leakage from a Geologic Disposal Reservoir, Including Transitions from Super- to Sub-Critical Conditions, and Boiling of Liquid $\mathrm{CO}_{2}$, Soc. Pet. Eng. J., pp. 237 - 248, June 2004. 
Pruess, K. Numerical Studies of Fluid Leakage from a Geologic Disposal Reservoir for CO2 Show Self-Limiting Feedback between Fluid Flow and Heat Transfer, Geophys. Res. Lett., Vol. 32, No. 14, L14404, doi:10.1029/2005GL023250, July 2005a.

Pruess, K. Numerical Simulations Show Potential for Strong Non-isothermal Effects During Fluid Leakage from a Geologic Disposal Reservoir for $\mathrm{CO}_{2}$, B. Faybishenko, P.A. Witherspoon and J. Gale (eds.), Dynamics of Fluids and Transport in Fractured Rock, Geophysical Monograph 162, pp. 81-89, American Geophysical Union, Washington, DC, $2005 b$.

Pruess, K. On CO2 Fluid Flow and Heat Transfer Behavior in the Subsurface, Following Leakage from a Geologic Storage Reservoir, Environmental Geology, in press, 2007.

Rutqvist, J. and C.F. Tsang. Coupled Hydromechanical Effects of CO2 Injection, in C.F. Tsang and J.A. Apps (editors), Underground Injection Science and Technology, Elsevier, pp. 649-679, 2005.

Rutqvist, J., J. Birkholzer, F. Cappa and C.-F. Tsang. Estimating Maximum Sustainable Injection Pressure during Geological Sequestration of $\mathrm{CO} 2$ Using Coupled Fluid Flow and Geomechanical Fault-Slip Analysis, Energy Conversion and Management, Vol. 48, pp. 1798-1807, June 2007.

Shipton, Z.K., J.P. Evans, D. Kirschner, P.T. Kolesar, A.P. Williams and J. Heath. Analysis of CO2 Leakage through 'Low-permeability' Faults from Natural Reservoirs in the Colorado Plateau, East-central Utah, in: S.J. Baines and R.H. Worden (eds.), Geological Storage of Carbon Dioxide, Geological Society, London, Special Publications, Vol. 233, pp. 43-58, London, England, 2004.

Skinner, L. CO2 Blowouts: An Emerging Problem, World Oil, Vol. 224, No. 1, 2003.

Stone, H.L. Probability Model for Estimating Three-Phase Relative Permeability, Trans. SPE of AIME, 249, 214-218, 1970. 
Streit, J.E. and R.R. Hillis. Estimating Fault Stability and Sustainable Fluid Pressures for Underground Storage of CO2 in Porous Rock, Energy, Vol. 29, pp. 1445-1456, 2004.

Todaka, N., S. Nakanishi, T. Tosha, T. Xu and K. Pruess. Natural Analogue Study for $\mathrm{CO}_{2}$ Geological Sequestration in the Matsushiro Field, Japan: Geochemical Modeling, presented at GHGT-8, 8th International Conference on Greenhouse Gas Control Technologies, Trondheim, Norway, June 2006.

Todesco, M., J. Rutqvist, G. Chiodini, K Pruess and C. Oldenburg. Modeling of Recent Volcanic Episodes at Phlegrean Fields (Italy): Geochemical Variations and Ground Deformation, Geothermics, Vol. 33, No. 4, pp. 531 - 547, August 2004. 


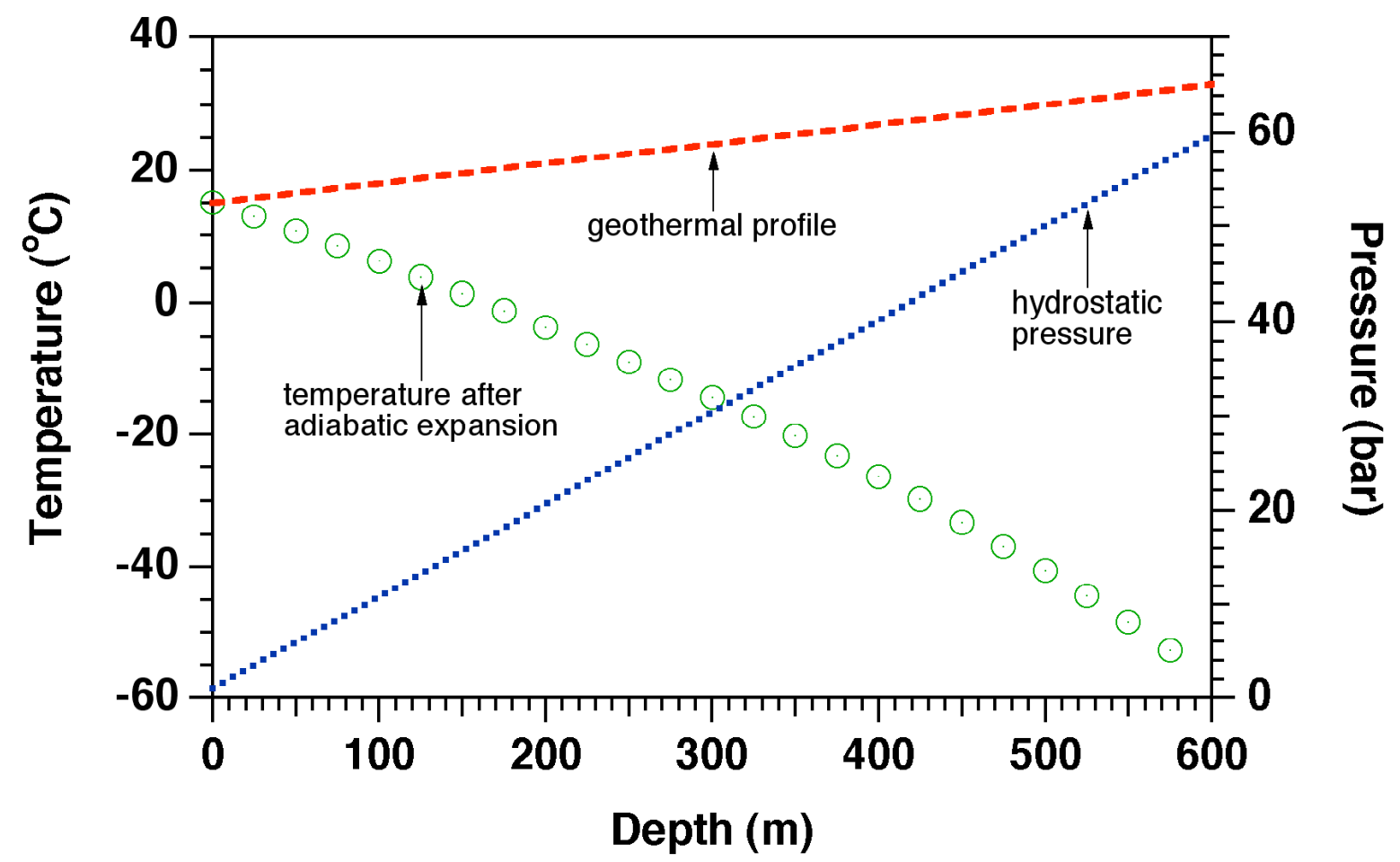

Figure 1. Cooling effects from adiabatic expansion of $\mathrm{CO}_{2}$ to atmospheric pressure (1.013 bar), starting from ambient hydrostatic-geothermal conditions at different depths.

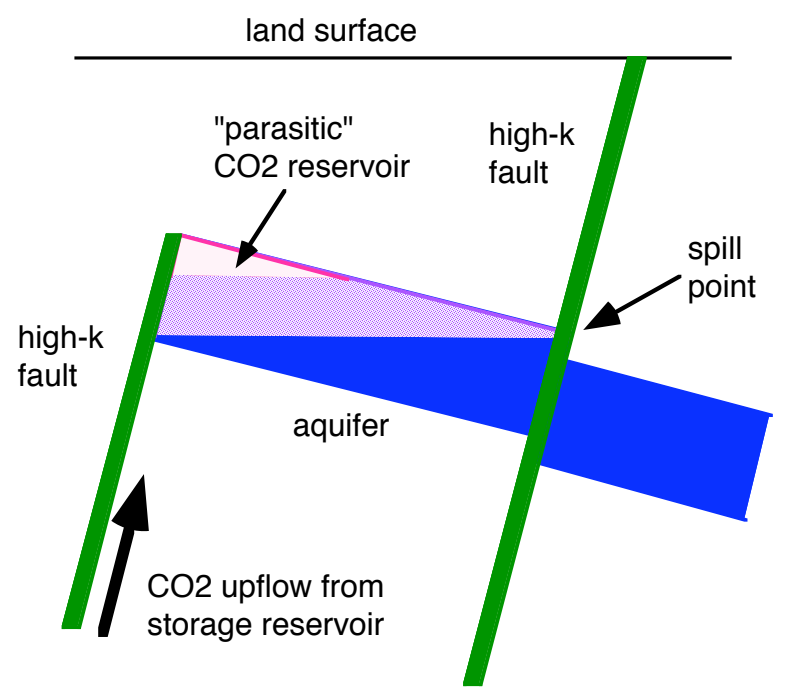

Figure 2. Conceptual leakage scenario that involves $\mathrm{CO}_{2}$ migrating up a fault to accumulate in a secondary "parasitic" reservoir at shallower depth. Discharge to the land surface can occur after the accumulation reaches a spill point where it can enter another fault. 


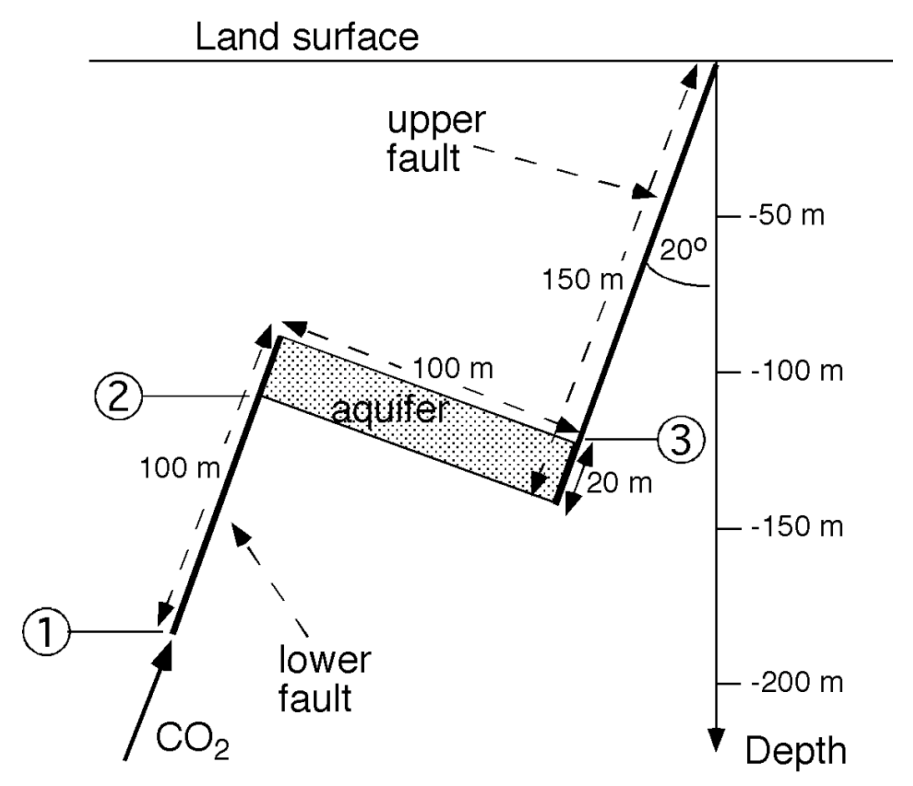

Figure 3. System dimensions as used for the reference case (no vertical exaggeration). Fault zone thickness is assumed as $2 \mathrm{~m}$, and a $1 \mathrm{~m}$ thick vertical section is modeled. (1) - (3) denote monitoring points.

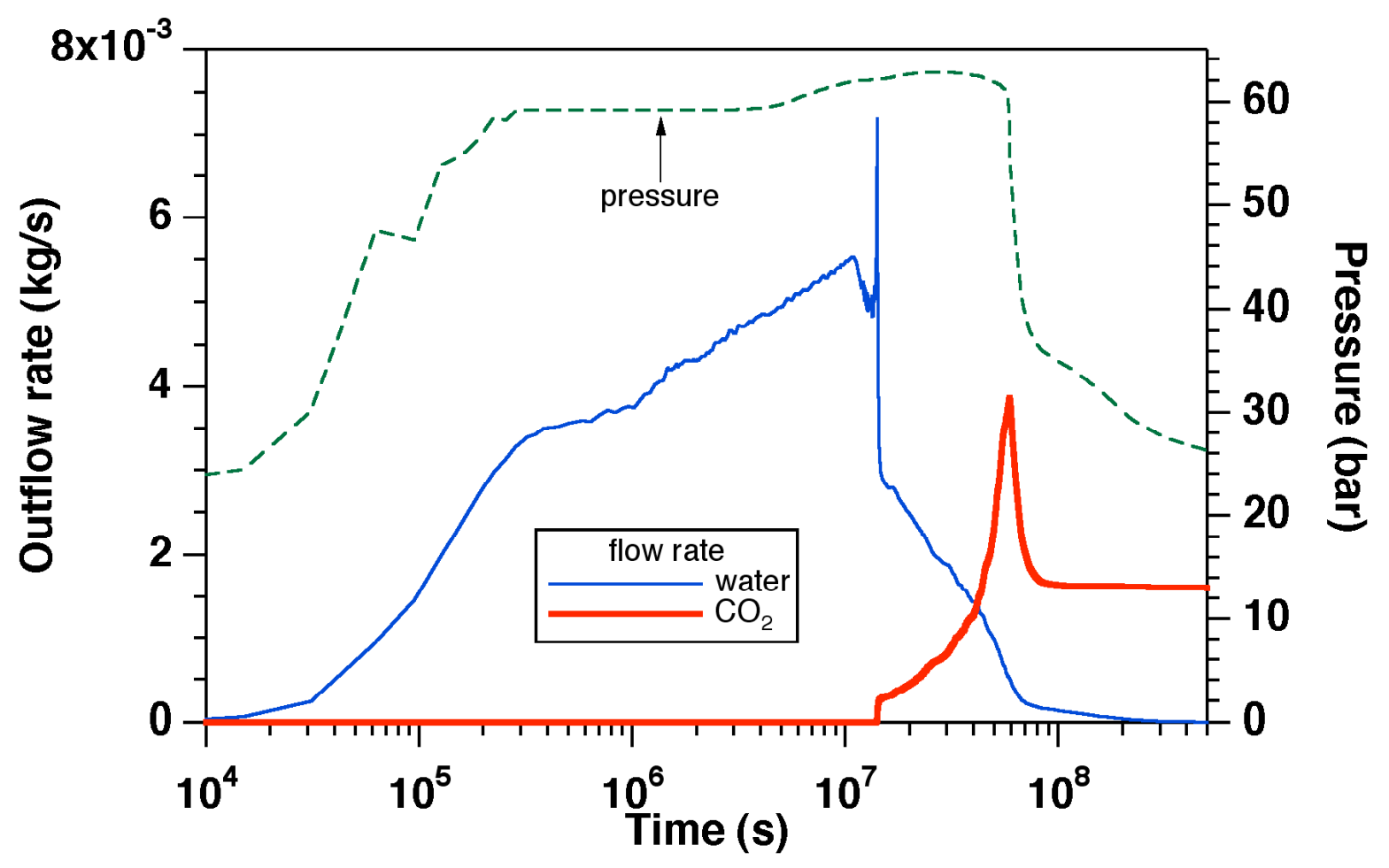

Figure 4. Water and $\mathrm{CO}_{2}$ discharges at the land surface, and fluid pressures at monitoring point (1). 


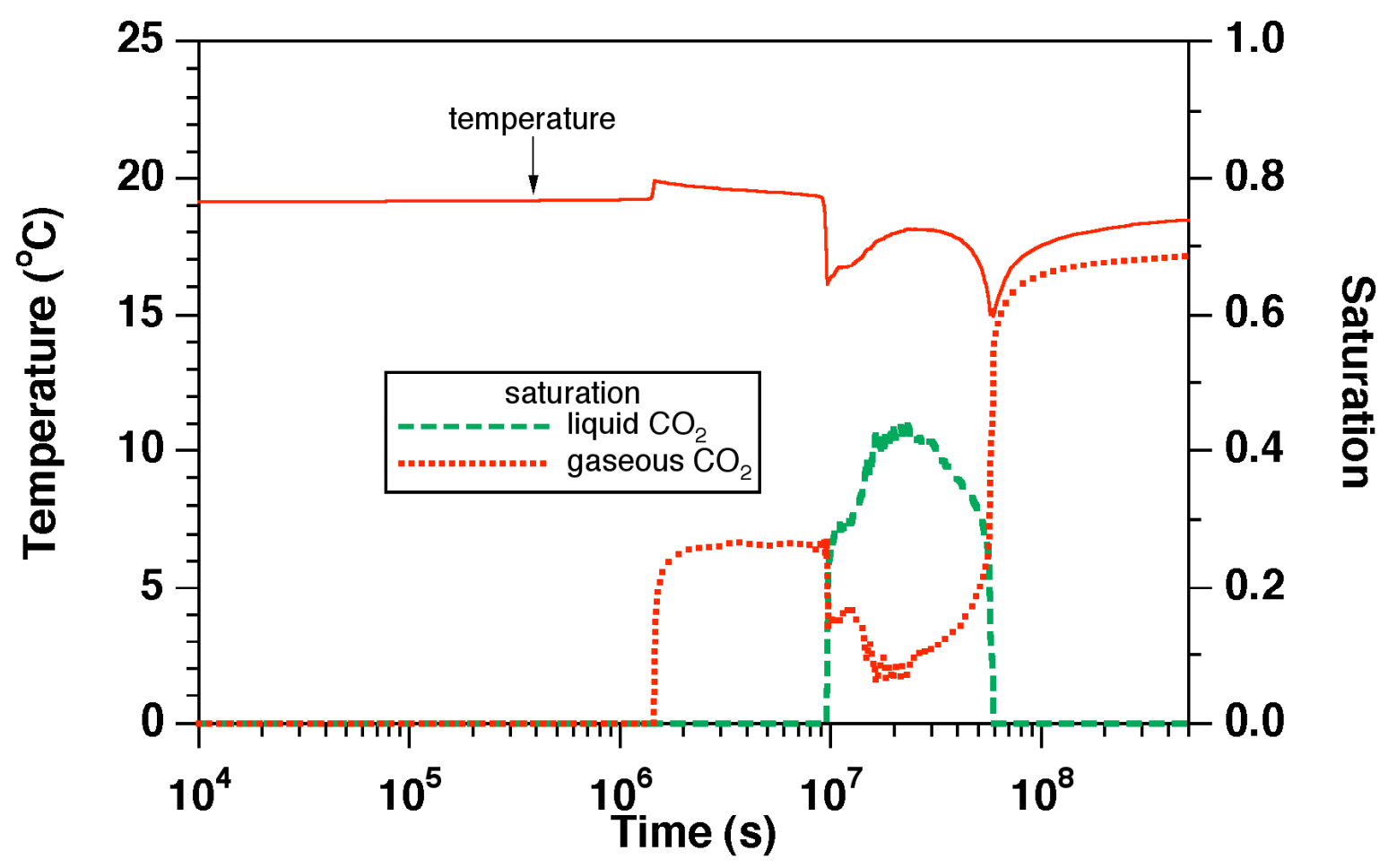

Figure 5. Evolution of temperatures and $\mathrm{CO}_{2}$ saturations at monitoring point (2).

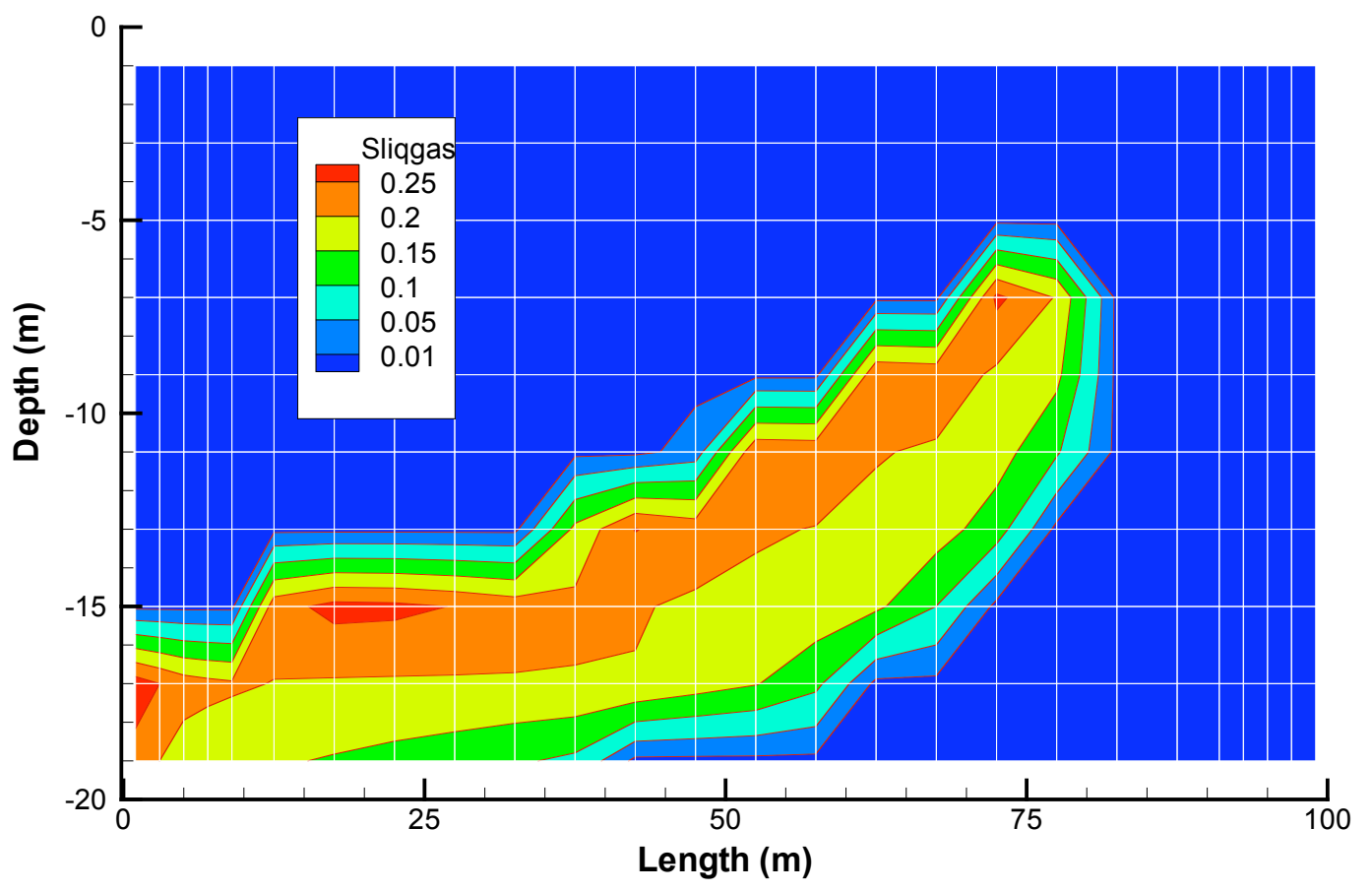

Figure 6. Extent of 3-phase conditions in aquifer at time $t=1.37$ years. Note the strong vertical exaggeration and the fact that the aquifer is rotated clockwise by $20^{\circ}$. 


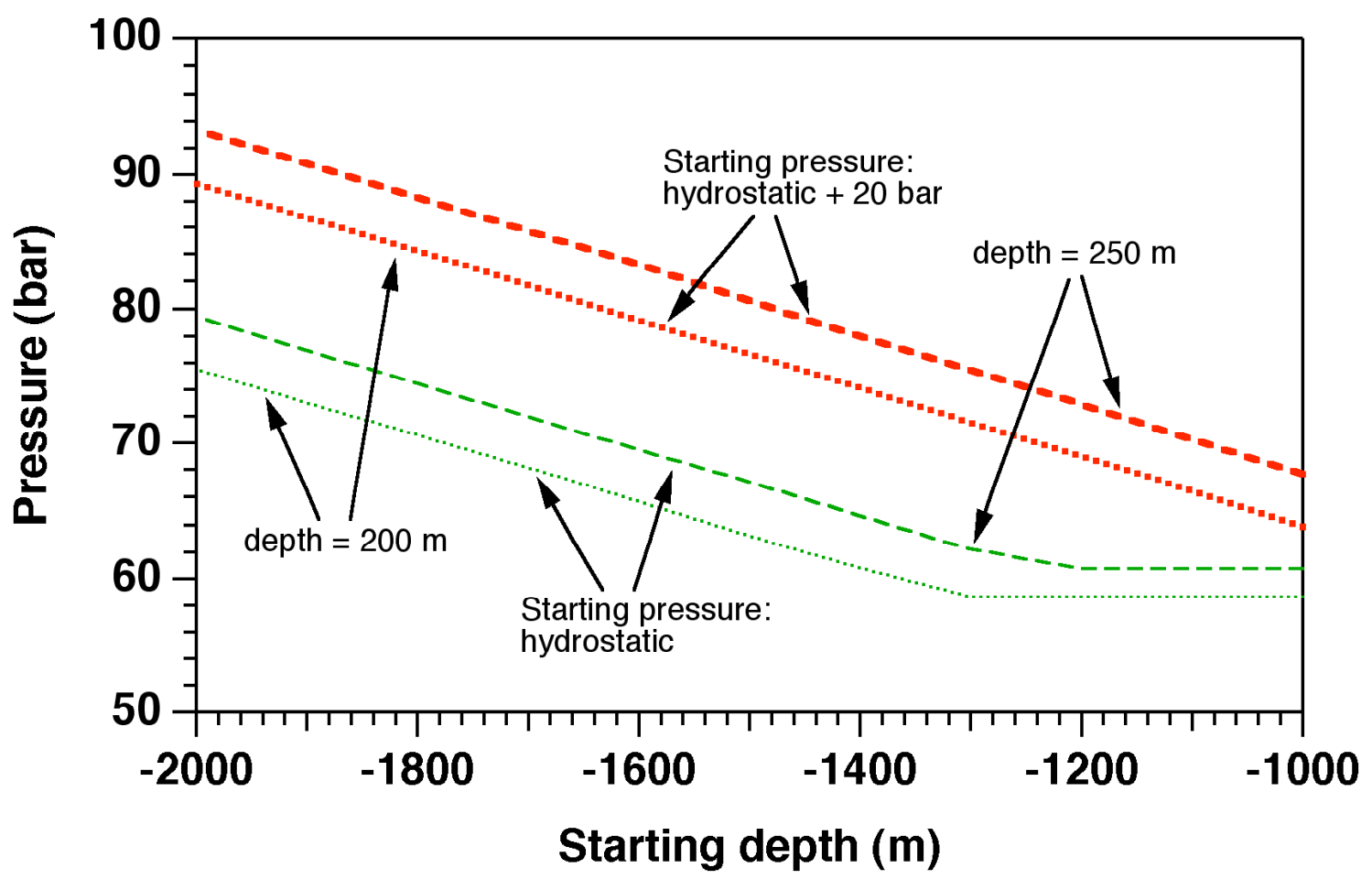

Figure 7. Pressures in static columns of $\mathrm{CO}_{2}$ at shallow depths.

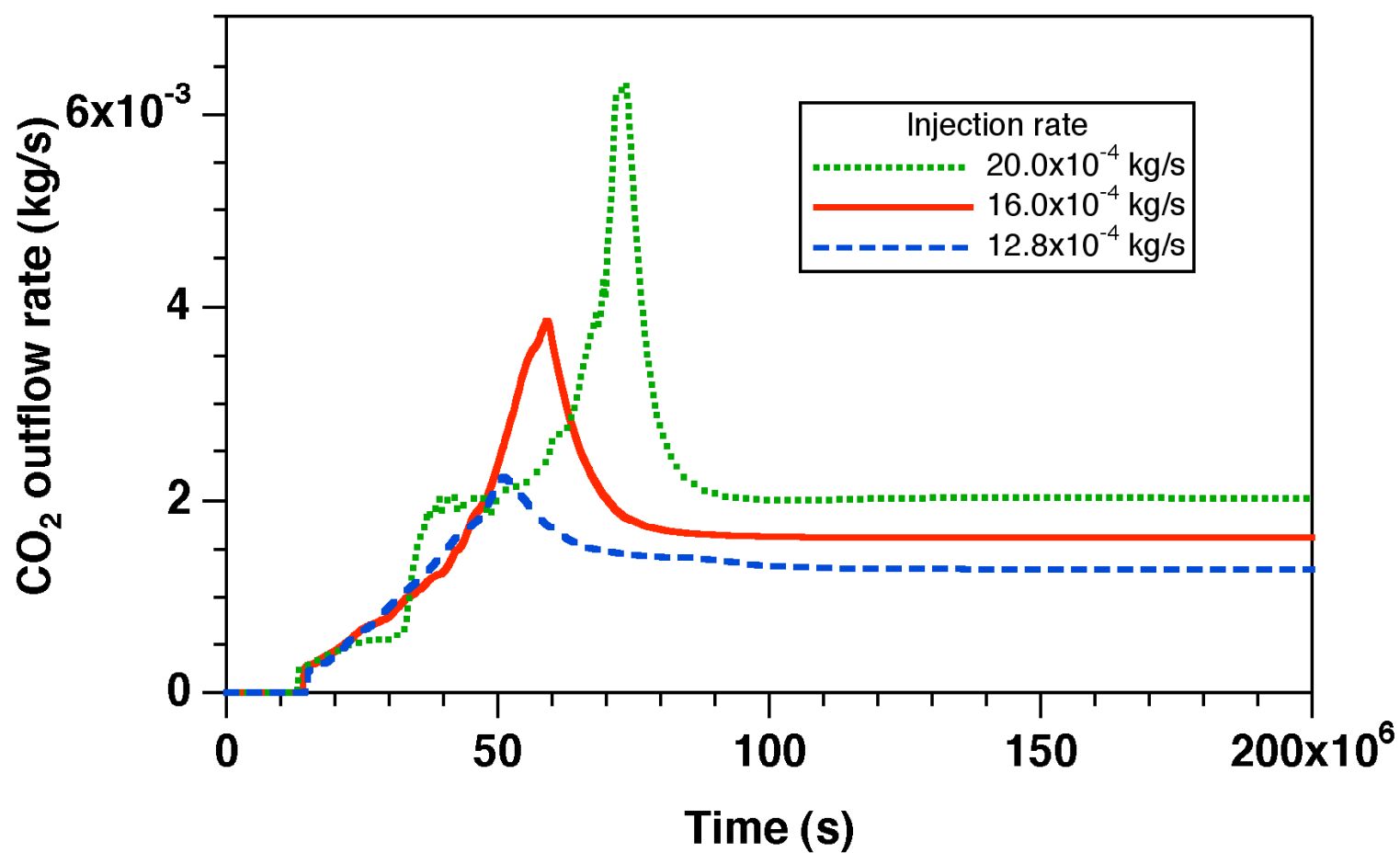

Figure 8. Dependence of $\mathrm{CO}_{2}$ outflow behavior on injection rate. 


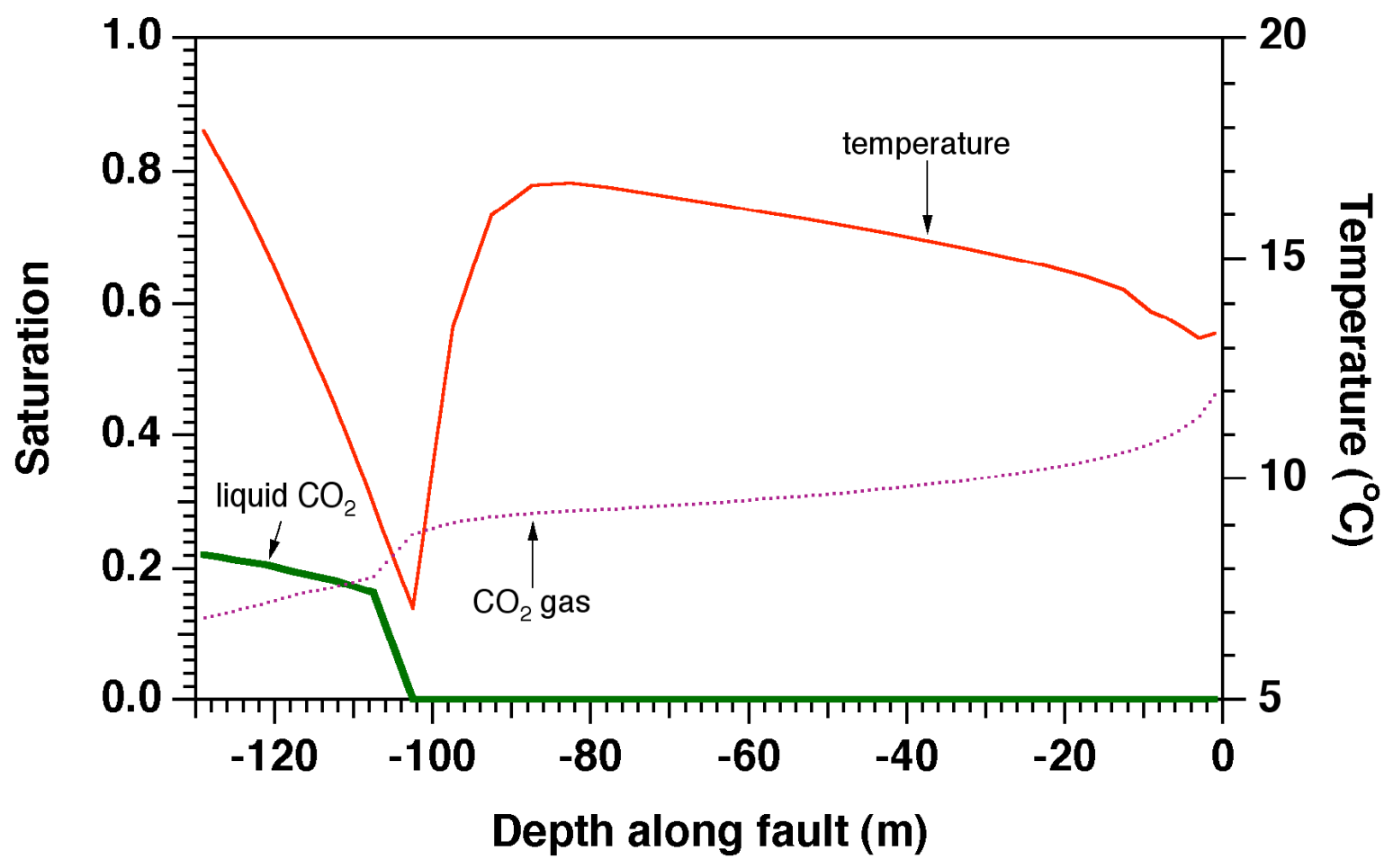

Figure 9. Profile of temperature and $\mathrm{CO}_{2}$ saturations in upper fault at $\mathrm{t}=1.50 \mathrm{yr}$.

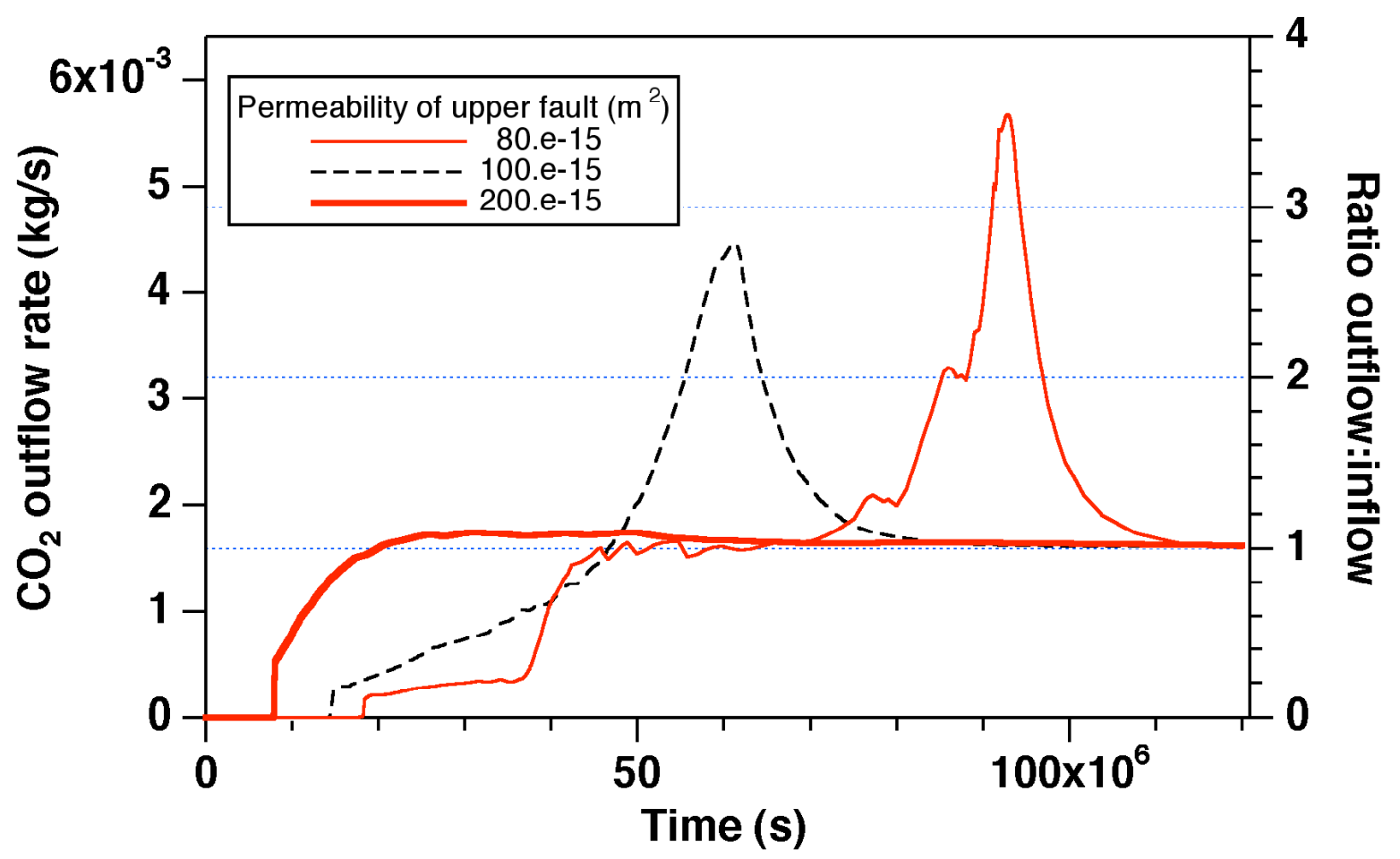

Figure 10. $\mathrm{CO}_{2}$ leakage behavior for different permeabilities of the upper fault. 


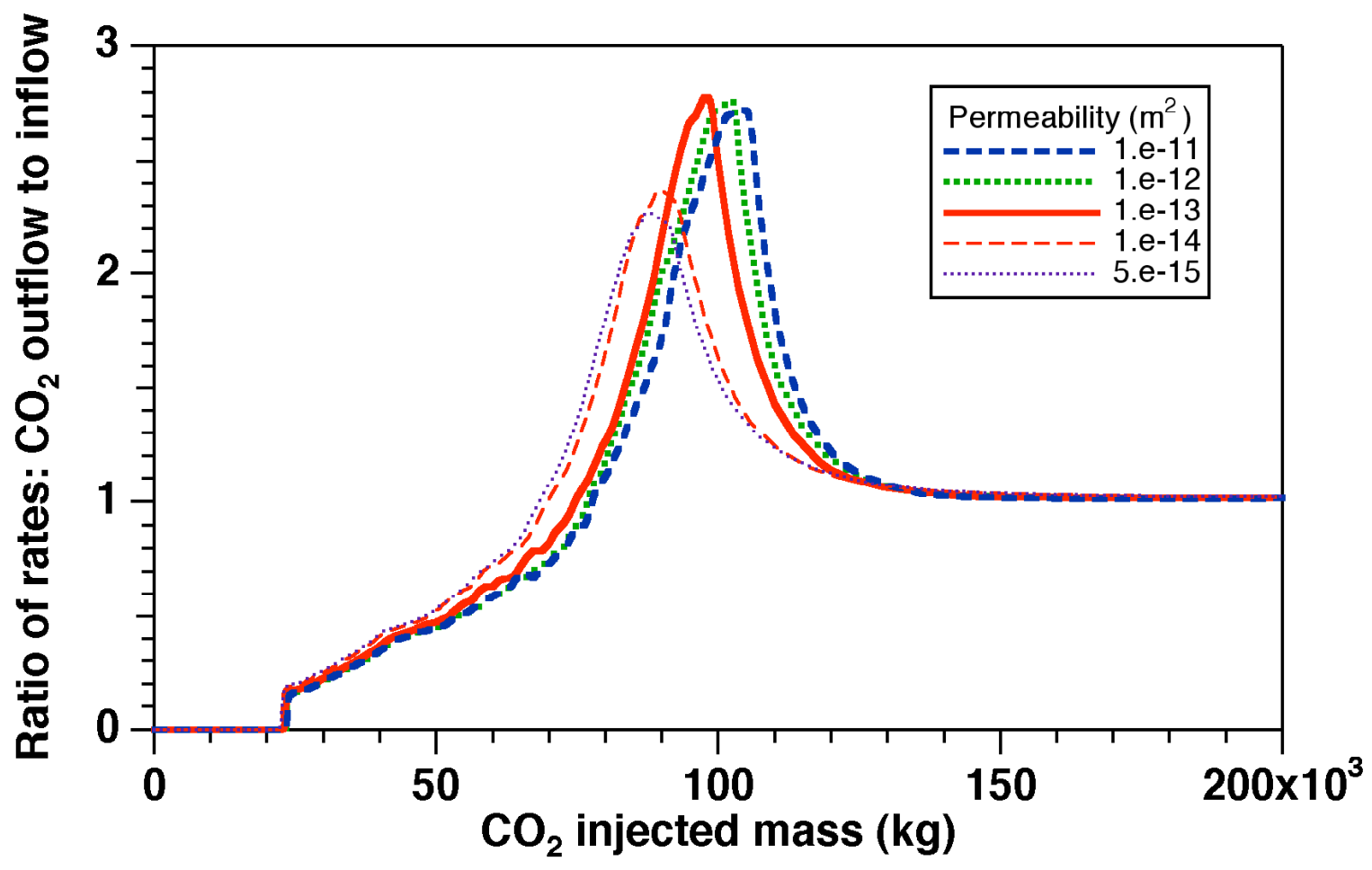

Figure 11. $\mathrm{CO}_{2}$ leakage behavior for systems with different permeability, holding the ratio of injection rate to permeability constant.

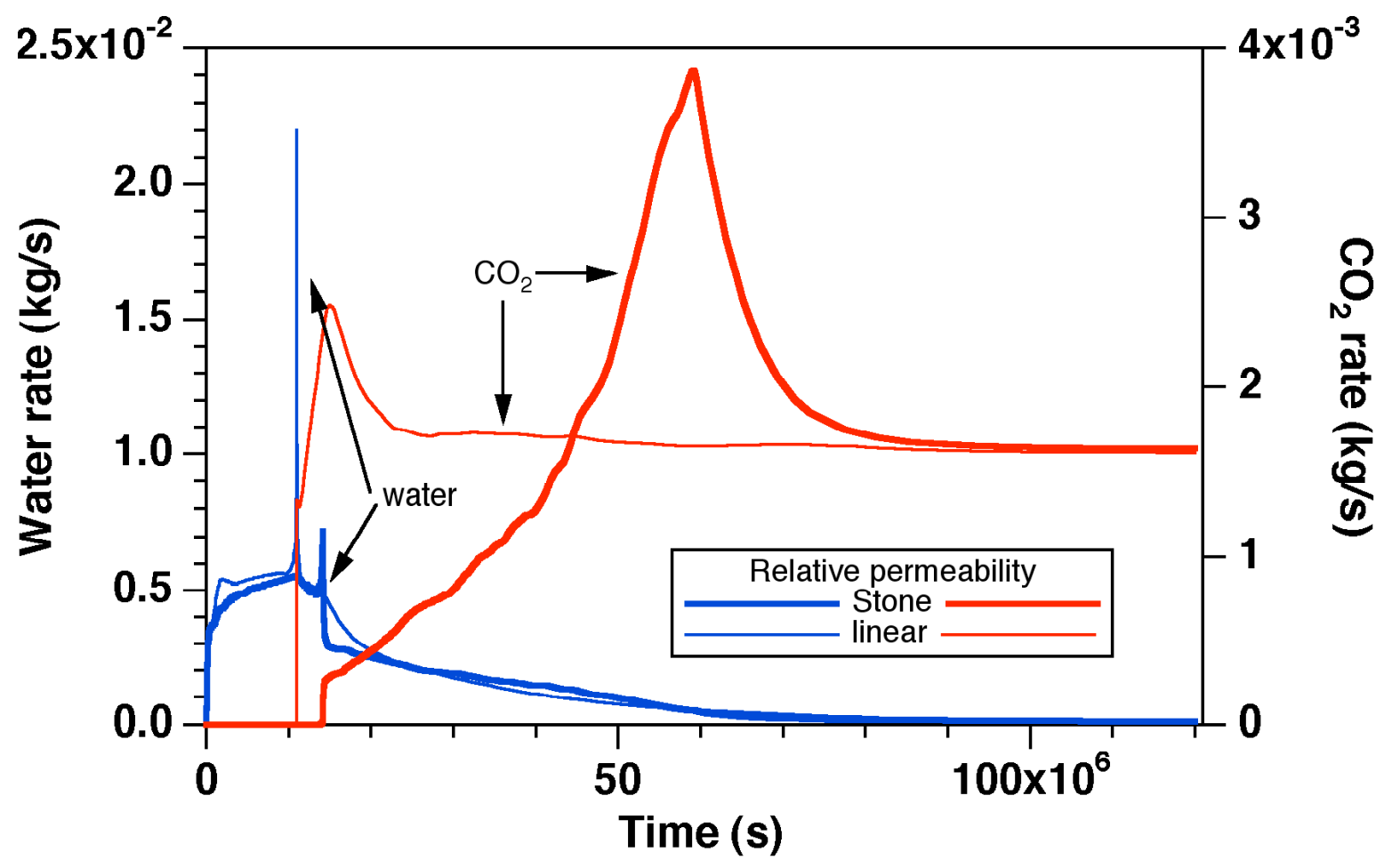

Figure 12. Sensitivity of water and $\mathrm{CO}_{2}$ discharge behavior to 3-phase relative permeability. 


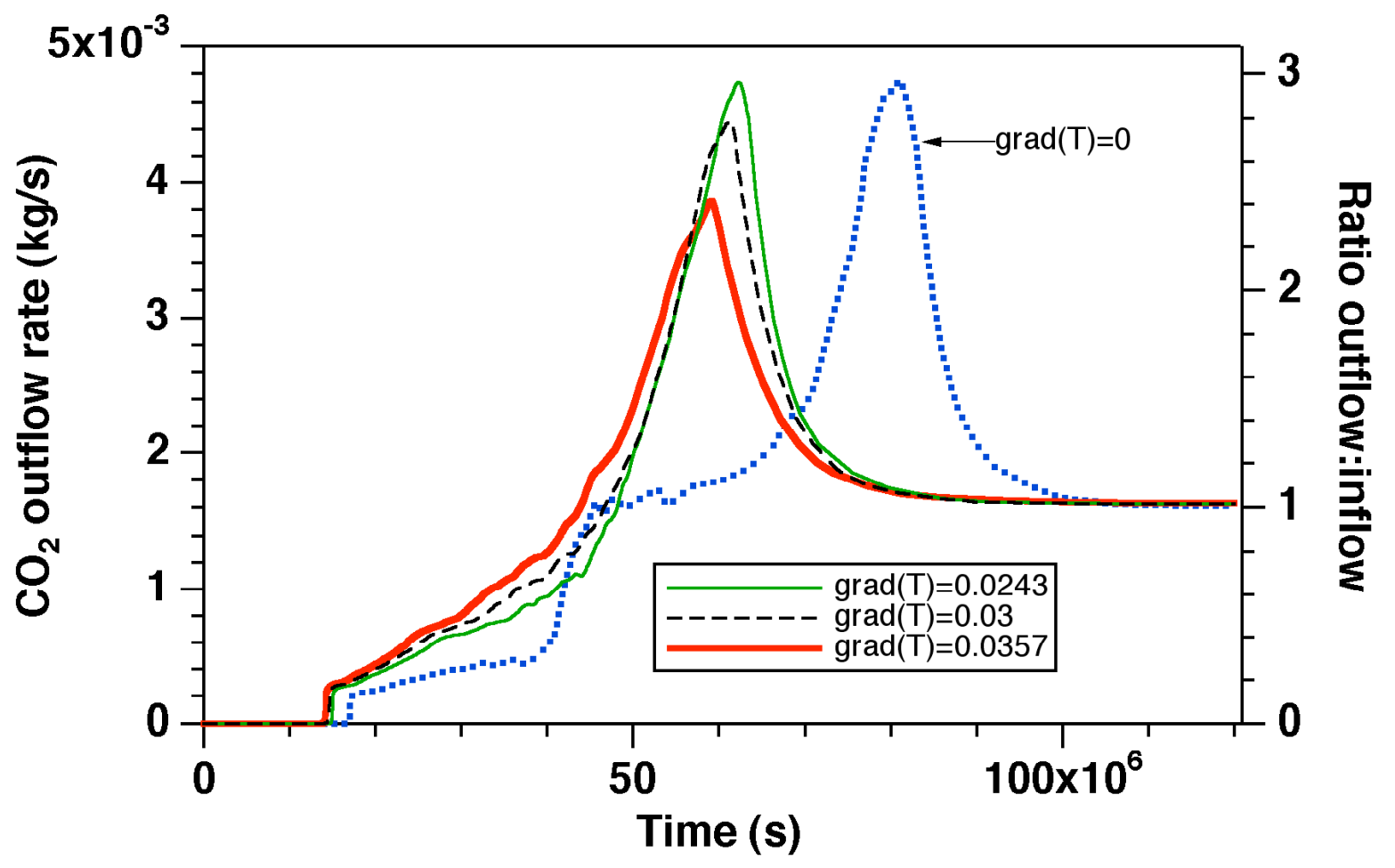

Figure 13. Sensitivity of $\mathrm{CO}_{2}$ discharge behavior to the geothermal gradient. 